\title{
Treeshelters for nursery plants may increase growth, be cost effective
}

\author{
Pavel Svihra $\square$ David W. Burger $\square$ Richard Harris
}

\begin{abstract}
We tested the efficacy of treeshelters on selected containergrown trees in the nursery and on redwood seedlings transplanted into the landscape. Treeshelters accelerated shoot growth of southern magnolia, holly oak and deodar cedar, but root growth was reduced during the first growing season as compared to the controls. Sufficient shoot-root development of the trees was achieved only after two growing seasons. One-year-old redwood seedlings successfully established themselves whether grown in treeshelters or not, while receiving $1 / 7$ to $1 / 14$ as much water as they would in a nursery bed grown in one-gallon containers. The seedlings in treeshelters grew significantly taller.
\end{abstract}

Despite innovative developments in propagating, growing and replanting container-grown ornamentals in the nursery, production costs remain high. Nursery managers, therefore, tend to grow only plants that perform reliably in containers and reach marketable size quickly. Furthermore, when transplanted to the landscape, ornamentals require several costly operations to be established successfully: site preparation, proper planting techniques, weed control, staking, protection from animal browsing and vandalism, and application of pesticides, fertilizers and irrigation.

Treeshelters (cylindrical polypropylene tubes about $10 \mathrm{~cm}$, or 4 inches, in diameter and of varying heights) have been broadly used in Great Britain and other countries to cut costs of establishing small (25- to 30- $\mathrm{cm}$, or 10- to 11-inch, tall) forest and landscape trees, and they could be cost-effective in California nurseries and landscapes. Trials conducted in England and elsewhere show that placing these shelters over just-replanted seedlings or naturally sprouted ones of various species improves the survival rate of seedlings.

Treeshelters protect seedlings against herbicidal drift and animal browsing, but their most attractive characteristic is the 60 to $600 \%$ plant growth increase that appears to result from their use. Rises in temperature, humidity and/or carbon dioxide $\left(\mathrm{CO}_{2}\right)$ concentration within treeshelters have all been suggested as probable causes for the increased growth. The nature of the relationship among these environmental parameters and their potential effect on treeshelter-grown plants is not clear.

The advantages of using treeshelters for growing plants in containers before transplanting have not been fully explored. It is not known how woody ornamentals respond to treeshelters in

California's wet winters and in its hot, almost rainless, summers. Replanted seedlings need particular attention under dry conditions.

We conducted studies to: (1) determine how trees would respond to being grown in treeshelters in nursery containers and after transplanting in the landscape, (2) monitor the environment in and around treeshelters used with container-grown trees, (3) measure the water use of trees in containers grown with or without a treeshelter and (4) compare the growth and survival of seedlings replanted into the landscape, grown with or without a

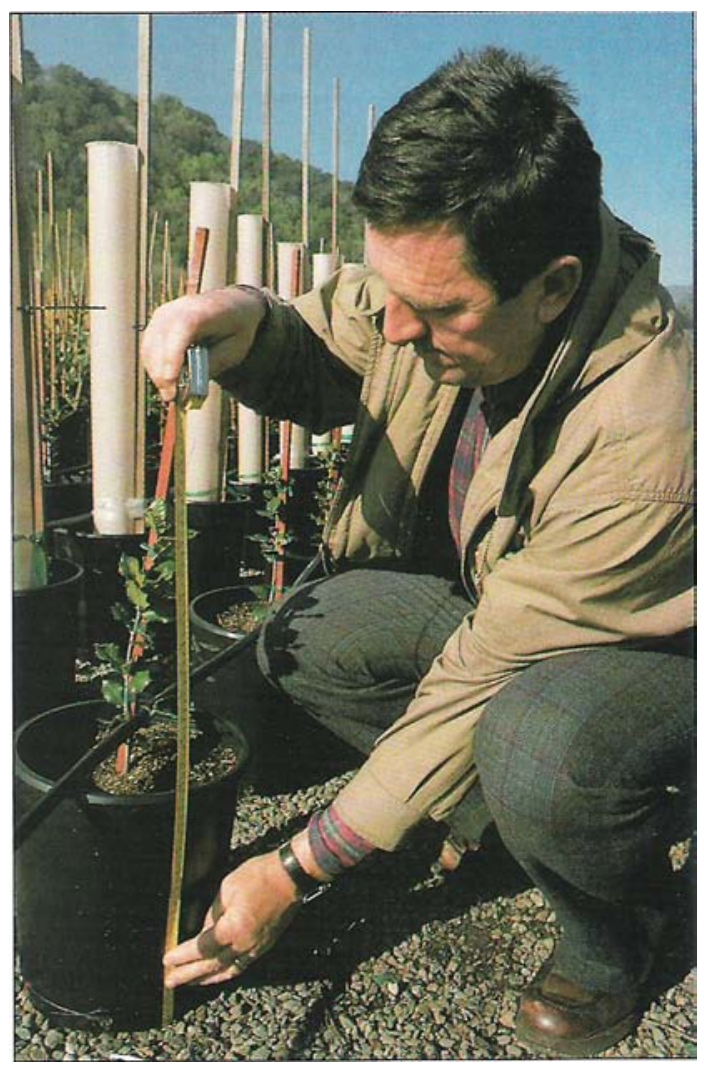

Physical setup of the treeshelter experiment (February 1990) showing the initial height of Quercus ilex.

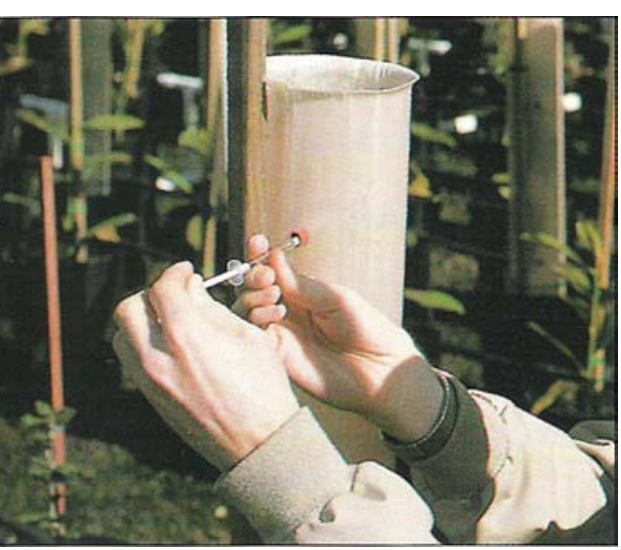

Gas sampling inside of the treeshelter with a 1-ml syringe through the septum.

treeshelter and receiving 7 or 14 times less water than in the nursery.

\section{Trees in nursery containers}

Methods. Three tree species were studied in the nursery: deodar cedar (Cedrus deodara), holly oak (Quercus ilex) and southern magnolia (Magnolia grandiflora). Thirty young plants of each of the three species grown in 1-gallon containers were transplanted into 5-gallon containers in February 1990.

Treeshelters (Tubex), each $91.5 \mathrm{~cm}$ (or 36 inches) long, were placed over 10 plants of each species. The bottom of each shelter 
was pushed approximately $3 \mathrm{~cm}(1.2$ inches) into the container medium, and each shelter was tied to a stake driven down alongside it.

All plants were arranged in east-west rows $(50 \mathrm{~cm}$ or 20 inches between rows and between plants). The northern- and out shelters (control plants), and the center row contained plants in shelters. Of the ten plants of each species in shelters, six were used to monitor the environment in and around the shelter. As a reference, five additional 5-gallon containers were each fitted with a treeshelter, but had no plants the five reference and six monitored treeshelters for each species and were plugged with septa to take gas $\left(\mathrm{CO}_{2}\right)$ samples from inside the shelters.

Plant height and trunk caliper (at the top of the pot) of each plant were measured at the beginning of the experiment and again at the end, on January 24, 1992. No trees were pruned during the experiment. Twice during the first growing season (April 13 and July 27, 1990), temperature, relative humidity and $\mathrm{CO}_{2}$ concentration were measured inside and outside the shelters.

Water use was measured twice during the first growing season (May 1 and June $7,1990)$. Plants were watered heavily and allowed to drain to container capacity ( 1 hour). The plant and container were weighed, placed back in the nursery bed, then weighed again after 24 hours. The difference in weight was defined as the water used, through transpiration by the southernmost rows contained plants withgrowing in them. Holes were drilled into

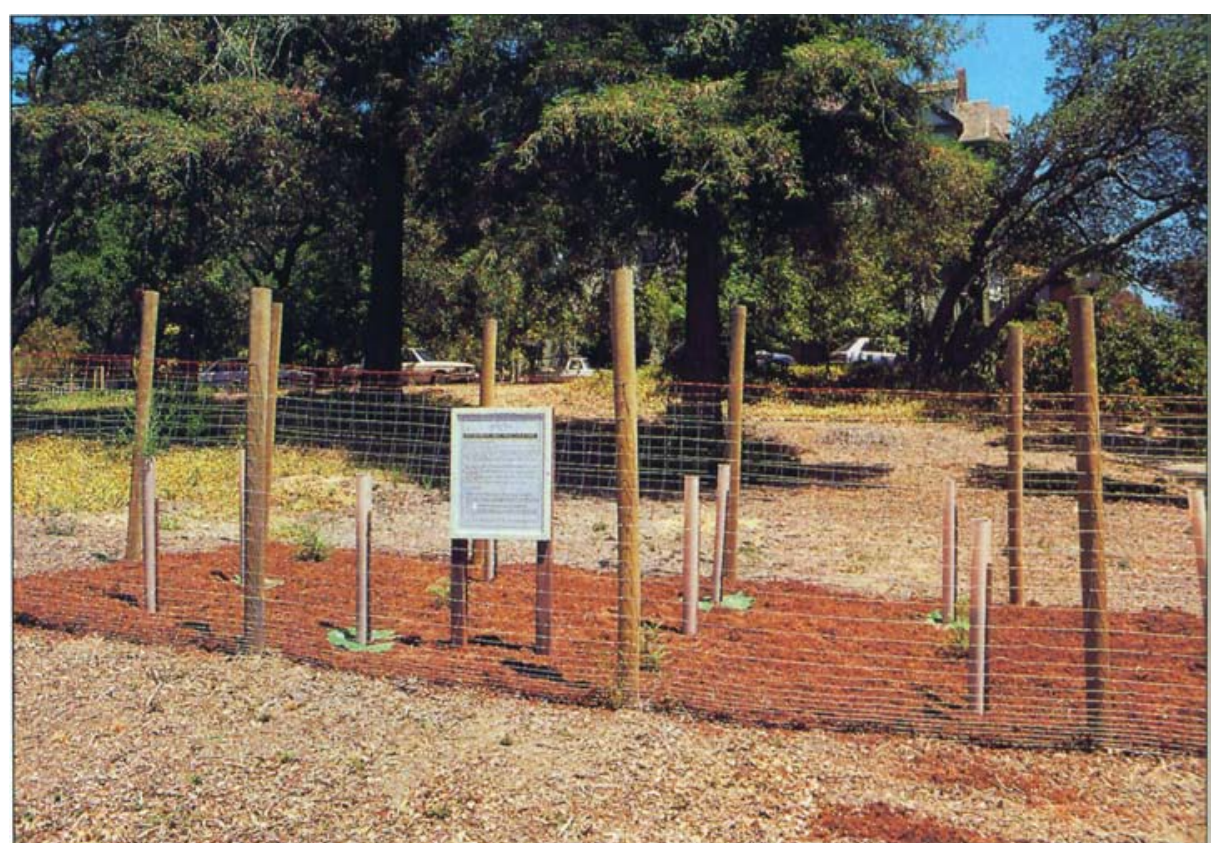

Treeshelter experiment setup in Falkirk Park, San Rafael. plant and evaporation from the soil surface.

In February 1991, a year after the experiment was established, sheltered trees of each species received the following treatments at random: (1) three trees were left in the shelters, (2) shelters and supporting stakes were removed from three trees and (3) shelters were removed from three trees and each was tied to a supporting stake. At the end of the experiment, we determined the fresh and dry weights of the tops and roots of all experimental plants. We weighed the roots after thoroughly washing the container medium
TABLE 1. Growth of three tree species after 2 years grown with and without treeshelters for 1 or 2 years

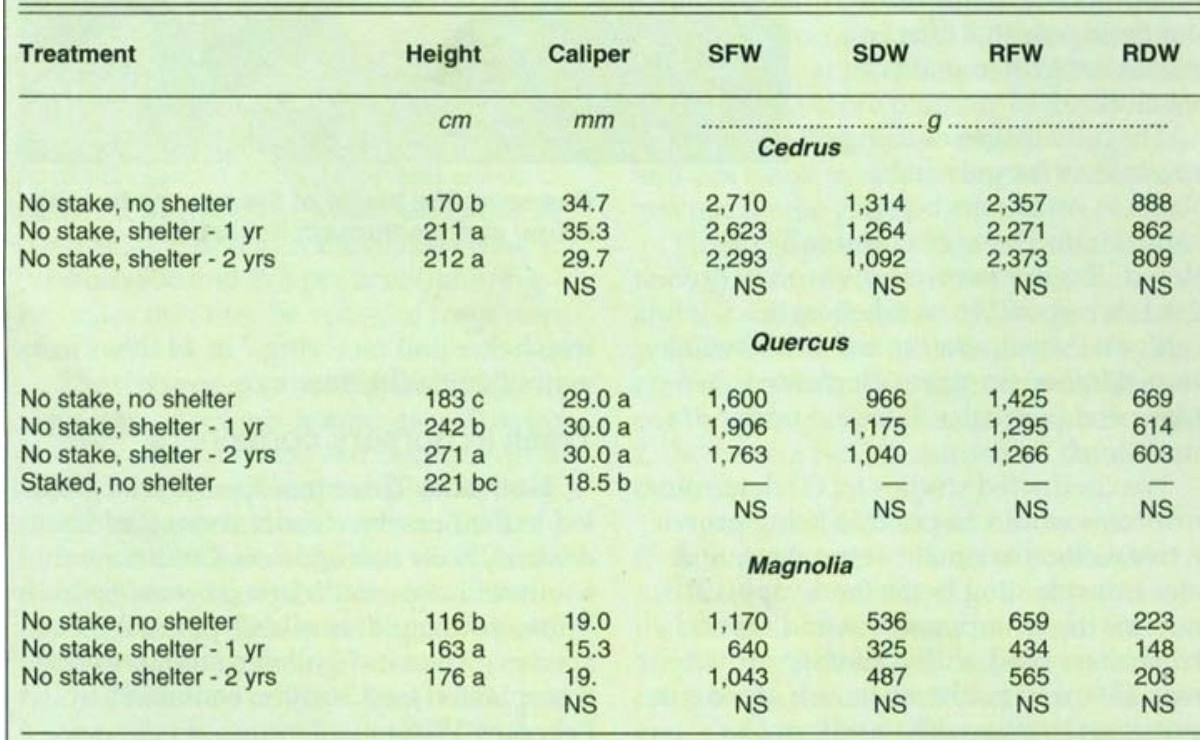

"Values in each parameter category for each species followed by the same letter are not significantly different at $p=0.05$ using Scheffe's Mean Separation Test. SFW = shoot fresh weight, SDW = shoot dry weight, RFW = root fresh weight, RDW = root dry weight, NS = not significant. away from the root systems. Dry weights were obtained after the plant material was dried in an oven at $70^{\circ} \mathrm{C}\left(158^{\circ} \mathrm{F}\right)$ for 7 to 10 days.

Results. Treeshelters raised the temperature, relative humidity and $\mathrm{CO}_{2}$ concentration around the trees. The air temperature and relative humidity inside the shelter were $3^{\circ} \mathrm{C}\left(5.5^{\circ} \mathrm{F}\right)$ and $19 \%$ higher, respectively, inside than outside the shelter $\left(32^{\circ}\right.$ versus $29^{\circ} \mathrm{C}$, or $90^{\circ}$ versus $\left.84^{\circ} \mathrm{F}\right)$ and 82 versus $61 \%$. The $\mathrm{CO}_{2}$ concentration was greater inside the shelter near the ground (435 ppm) and decreased with height to $364 \mathrm{ppm}$ at the top. The concentration outside the shelters was $362 \mathrm{ppm}$.

The height of all three species grown in shelters for 1 year was greater than that of unsheltered control trees (table 1). The height increase difference between sheltered and unsheltered Quercus trees continued through the second year but did not for Cedrus and Magnolia.

Quercus trees that had been staked but unsheltered for 2 years were shorter than those that had grown in shelters for 2 years. Staked Quercus trees had smaller caliper diameters than unstaked trees. Staking did not significantly affect either of the other two tree species. Neither fresh weights nor dry weights of shoots and roots after 2 years were significantly affected by treeshelter treatment. Some leaves of Magnolia trees growing in treesheiters fell off.

Cedrus trees grown in shelters used significantly less water than those grown without shelters ( 353 versus $577 \mathrm{ml} / 24 \mathrm{hr}$, or 11.9 versus $19.5 \mathrm{oz} / 24 \mathrm{hr}$ ). Even though Magnolia and Quercus trees in shelters used less water than those without shelters ( 253 to 337 and 340 to $367 \mathrm{ml} / 24 \mathrm{hr}$, respectively), the differences were not sta- 
tistically significant. (In English measure, water used was 8.5 to $11.4 \mathrm{oz} / 24 \mathrm{hr}$ in trees with shelters and 11.5 to $12.4 \mathrm{oz} / \mathrm{hr}$ in trees without).

Increases in growth of trees grown in shelters may be partly due to increases in temperature, relative humidity and $\mathrm{CO}_{2}$ concentration. Similar conclusions were reported by other researchers. Light intensity and quality are also altered when passing into the treeshelter. The manufacturer states that light intensities can be reduced $40 \%$, and this may be partly responsible for the elongation response observed. in our trees.

The change in shoot/root ratio suggests a differential partitioning of photosynthate. It appears that shoot growth is promoted while root growth is inhibited in trees grown in treeshelters. This problem may diminish as the tree grows out of the top of the shelter during the second and third year in the nursery and/or in the landscape. The reduced root growth is of most concern because of possible effects on the ease and success in transplanting.

\section{Landscape trees in a park}

Method. Fifteen seedlings of coast redwood (Sequoia sempervirens), seeded on May 5, 1989, were selected at random on May 10, 1990, from flats in the forest nursery at the California Department of Forestry and Fire Protection, Davis. They were taken on the same day to Falkirk Park in San Rafael and planted in three north-south rows $(150 \mathrm{~cm}$ or 59 inches between plants). Before the treeshelters were erected, height and trunk caliper were measured for each experimental plant. Ten treeshelters were placed over randomly selected seedlings; five were marked with a dot and five with an asterisk around which growth-ring watering tubes were installed. (Because the water release significantly varied between the tubes, we left them on the site but did not use them

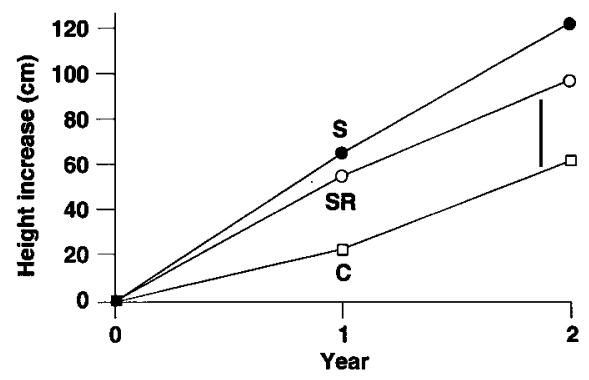

Fig.1. Growth responses of Sequoia sempervirens seedlings grown with and without treeshelters after each seedling in group "S" received 1 liter of water each 14th day; group "SR" received 1 liter of water each 7 th day; and group " $\mathrm{C}$ " control/unprotected seedlings received a similar schedule as the "SR" group. The vertical bar indicates one standard deviation.

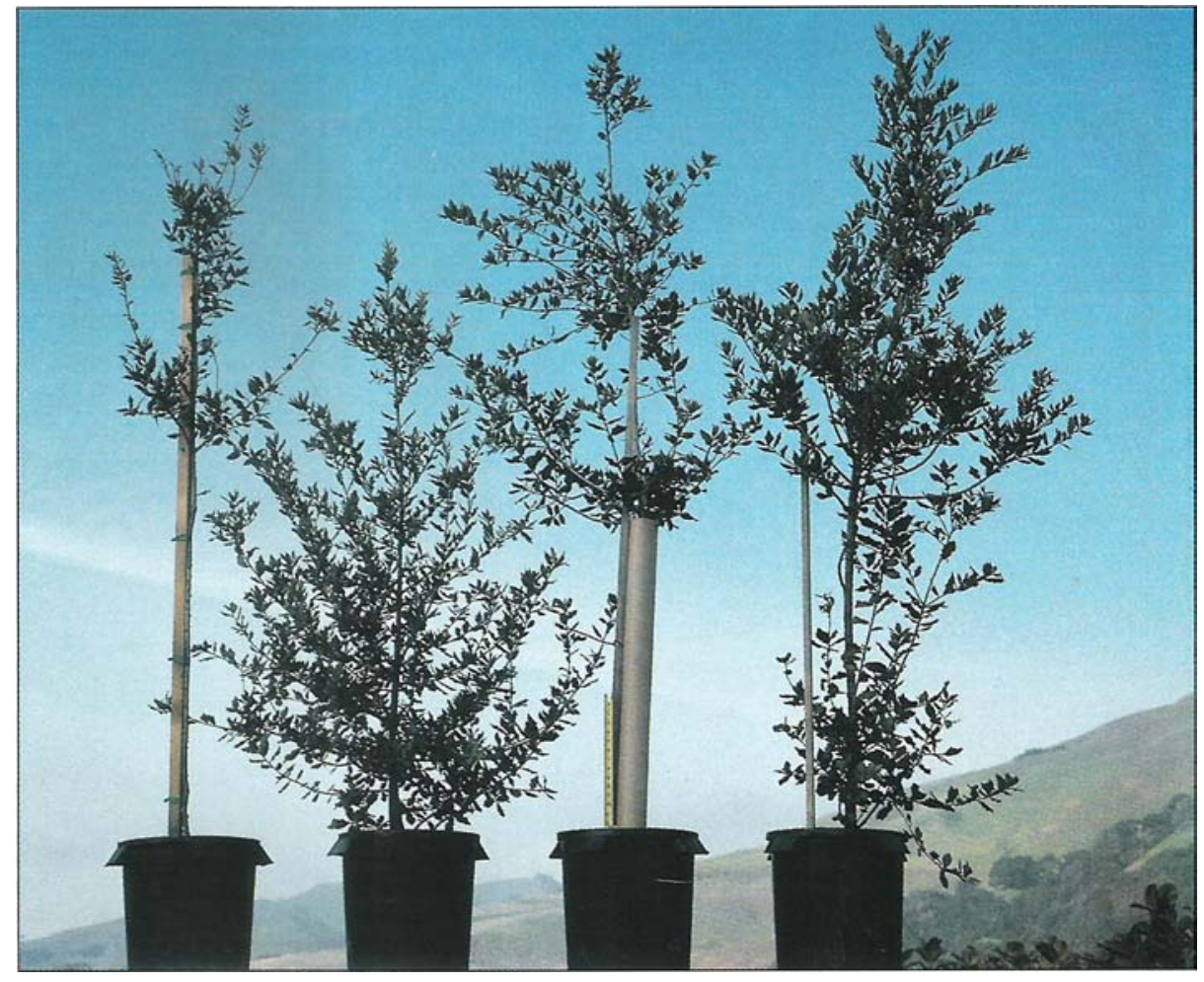

Growth response from February 1990 to January 1992 of Quercus ilex trees grown with a stake (first left), without (second left), with a treeshelter (third left), with a treeshelter the first year and without a treeshelter the second year (fourth left). Tape measure shows the initial height of trees.

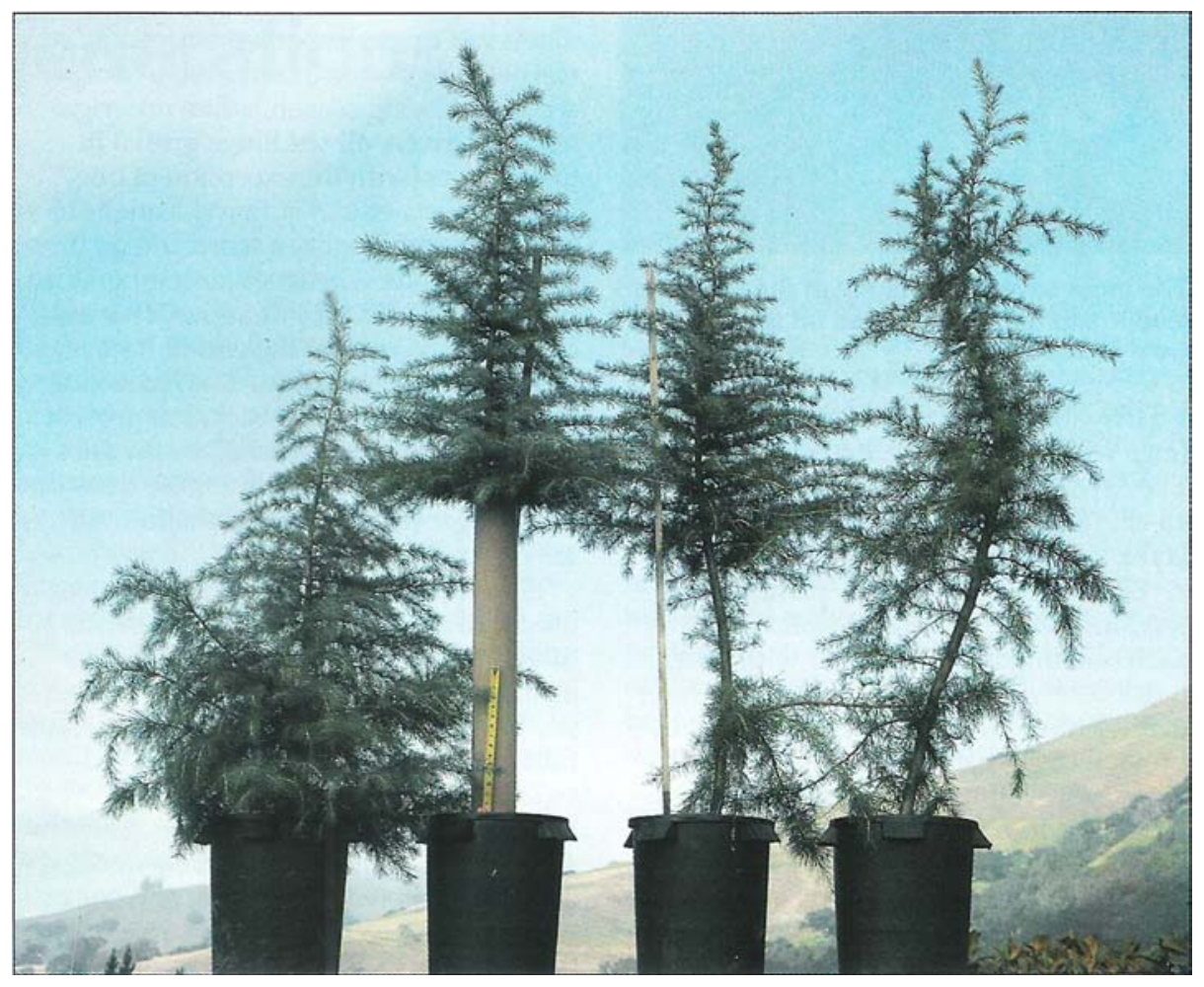

Growth response from February 1990 to January 1992 of Cedrus deodara trees grown without a treeshelter (first left); with a treeshelter (second left); with a treeshelter the first year and without a treeshelter but supported with a stake in the second year (third left); with a treeshelter the first year and without a treeshelter or stake the second year (fourth left). Tape measure shows the initial height of the trees. 


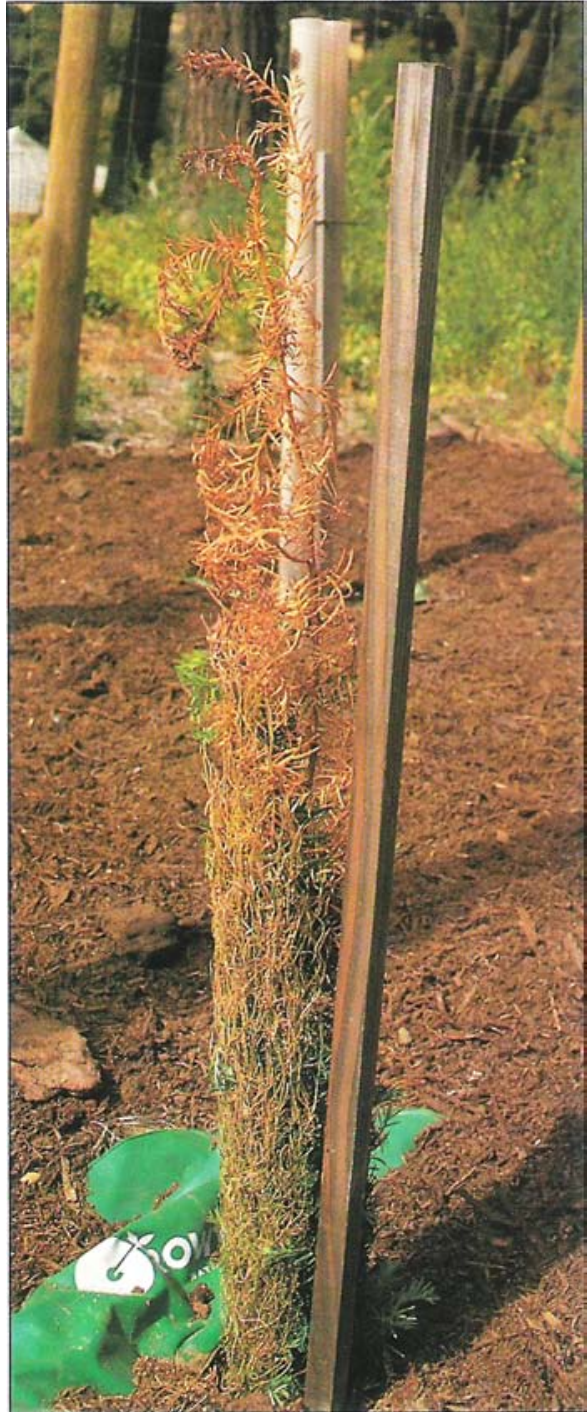

The most severe scorching of the redwood leader and foliage occurred on the southwest exposure.

for irrigation.) The remaining five seedlings were left unprotected as controls. The experimental plot was mulched with a 15-cm (6-inch), shredded, redwood bark layer.

Beginning 14 days after planting, the seedlings were irrigated as follows: (1) each seedling in a treeshelter with an asterisk received 1 liter (about $1 \mathrm{gt}$ ) of water every 7 days (SR-schedule established by previous trials as the amount normally required for wetting the 8-cm-deep root system in the local heavy clay soil), (2) each seedling in a treeshelter with a dot received less water, 1 liter every 14 days (Sschedule) and (3) control seedlings received 1 liter of water every 7 days. These irrigation schedules ended on October 29, 1990 , when the first rain occurred in the area. After that, the plants were left to adjust their growth and survival to the water supply from natural precipitation.
Seedlings were checked weekly during the growing season and biweekly in fall and winter or immediately after any unusual storm, freeze or very high temperature. Height and trunk caliper were remeasured on April 10, 1991, and on May 27, 1992.

Results. Redwood seedlings protected by treeshelters and irrigated with 1 liter of water every 14 days (S-schedule) grew significantly higher than the unprotected control seedlings, which received 1 liter of water every 7 days (fig. 1). Protected seedlings irrigated with 1 liter of water every 7 days, SR-schedule, were 26 to $28 \%$ shorter than those in treeshelters with the S-schedule. Seedlings with the SR-schedule were about 60 to $63 \%$ taller than the unprotected control seedlings under the same watering schedule, but this difference was not significant. Neither treeshelters nor watering schedule had a significant effect on caliper, although in the second growing season, control seedlings had about 26 to $31 \%$ larger caliper than those in treeshelters.

During the first year, when seedlings were irrigated, all seedlings, protected and unprotected by a treeshelter, had a healthy green color. During the second half of December 1990, an unusually long and severe freeze killed one seedling in a treeshelter and one in an unprotected control group. All seedlings in treeshelters displayed tip dieback on their foliage; control seedlings were unaffected. During the second growing season, when no irrigation was given, all seedlings grown in treeshelters (with the exception of one with the S-schedule) suffered leader dieback and severe foliage scorching on their southwest side whenever air temperature reached $37^{\circ} \mathrm{C}\left(98.6^{\circ} \mathrm{F}\right)$ or above. This occurred twice, once at the end of June and again in September 1991. The redwoods recovered from this dieback, but growth was reduced in the treeshelters. In the third growing season, only those trees that had not grown out of their shelters suffered scorching damage.

The experiment in Falkirk Park was used as a model demonstration site for 20 other groups in California, which established their own treeshelter sites. At one site in Lafayette (with harsher temperature fluctuations than at Falkirk Park), redwood seedlings were planted and treeshelters were combined with growthring watering tubes (each tube was filled every 14 days with 22.7 liters, or $6 \mathrm{gal}$, of water, receiving 20 to 22 times more water than seedlings in Falkirk Park). No seedling displayed scorching, but none has grown taller than those in Falkirk Park. When checked at 2 p.m., treeshelters in Falkirk Park had no water condensation on the walls; in Lafayette, they always did.

\section{Conclusions}

Container-grown plant responses in our study indicate that treeshelters may have an application in the nursery. The treeshelters accelerated shoot growth of $M$. grandiflora, Q. ilex and C. deodara, although root growth was reduced during the first growing season after treeshelters were installed. The 74 to $174 \%$ increases in height are attractive enough to encourage nursery managers to try some slow-growing woody ornamentals in treeshelters. It will be necessary, however, to investigate the suitability of container-grown plants in treeshelters for transplanting, as our data show that one growing season seems to be satisfactory for shoot growth but insufficient for normal root development. Specifically, nursery managers need information on how to incorporate treeshelters into nursery production, in which pruning, replanting to larger containers and the like are critical to producing high-quality plants. Also, trials are needed to identify species unsuitable for treeshelters.

Our landscape experiment with 1-yearold seedlings of $S$. sempervirens, suggest that these trees, when planted by standard procedures, successfully establish themselves whether grown in treeshelters or not. Interestingly enough, they received $1 / 14$ to $1 / 7$ as much water as they would have in a nursery bed grown in 1-gallon containers. No seedling death or foliage scorching was observed during the first year of the watering schedule in these landscape-grown seedlings. The seedlings in treeshelters that received 1 liter of water each fourteenth day grew significantly taller than the control/unprotected ones that received 1 liter of water each seventh day.

Lack of irrigation in the second growing season reduced growth rate increases in all experimental trees, but did not cause tree mortality. The redwoods protected in treeshelters were severely scorched, however, and in some cases their leaders were killed in the heat. This important observation shows that it is not clear how seedlings in treeshelters would respond to hot, dry, California summers.

P. Svihra is Horticulture Advisor, Marin and Sonoma counties; D. W. Burger is Associate Professor, Department of Environmental Horticulture, UC Davis, and R. Harris is Professor Emeritus, Department of Environmental Horticulture, UC Davis.

This work was funded partially by the California Association of Nurserymen. The authors would like to acknowledge the support of the city of San Rafael for setting up the experimental site, Tubex (Saint Paul, Minnesota) for supplying the treeshelters and Pacific Nursery (Sunol, California) where all nursery experiments were conducted. 